\title{
A prospective observational study to determine the utility of placental laterality for prediction of preeclampsia in pregnancy
}

\author{
Anshul Rana*, Rama Thakur, Rohini Rao
}

Department of Obstetrics and Gynecology, Kamla Nehru State Hospital for Mother and Child, Indira Gandhi Medical College, Shimla, Himachal Pradesh, India

Received: 06 February 2020

Accepted: 29 February 2020

*Correspondence:

Dr. Anshul Rana,

E-mail: anshulrana10july@gmail.com

Copyright: (C) the author(s), publisher and licensee Medip Academy. This is an open-access article distributed under the terms of the Creative Commons Attribution Non-Commercial License, which permits unrestricted non-commercial use, distribution, and reproduction in any medium, provided the original work is properly cited.

\section{ABSTRACT}

Background: Preeclampsia is a multisystem disorder of unknown aetiology and recently its link with placental laterality has been explored. The objective of this study was to find the association of placental laterality with maternal and fetal outcomes in pregnancy. Study also determined the predictive ability of placenta laterality for the development of hypertension in pregnancy.

Methods: A prospective observational cohort study was conducted on 200 pregnant women. Routine investigations and doppler analysis were done. Placenta position was categorized into central and lateral. Maternal and fetal outcomes were recorded. The data was entered in MS excel spreadsheet and analysis was done using statistical package for social sciences (SPSS) version 21.0. A p value of $<0.05$ was considered statistically significant.

Results: Study found no significant association of placental laterality with hypertension in pregnancy. Various fetal complications, birth weight, Apgar scores and NICU admission were comparable among women with central or lateral placenta $(p>0.05)$. Even the maternal outcomes like mode of delivery, onset of labor, indication of labor induction and caesarean deliveries were comparable among women with central or lateral placenta $(p>0.05)$. On applying univariate logistic regression analysis, previous history of hypertension in pregnancy was a significant risk factor for development of preeclampsia with odds ratio of $168.43(\mathrm{p}<0.05)$.

Conclusions: It can be concluded that the maternal and fetal outcomes are independent of the placenta laterality. The doppler characteristics and placenta laterality did not show any increased risk for hypertension in pregnancy. However future studies are recommended with large sample size including more women with diagnosed hypertension in the pregnancy so that a better association can be derived with placenta laterality and doppler characteristics.

Keywords: Doppler, Hypertension, Placenta laterality, Pregnancy

\section{INTRODUCTION}

Preeclampsia is a multisystem disorder of unknown aetiology; it is the principle and most frequent medical complication in pregnancy leading to maternal and perinatal morbidity and mortality. It complicates $5-10 \%$ of pregnancies worldwide. ${ }^{1}$ In India incidence of preeclampsia is reported to be $8-10 \%$ in pregnant women. ${ }^{2}$ Given that timely and effective care can improve the outcome of preeclampsia, the development of effective prediction and prevention strategies has been a major objective of prenatal care research. ${ }^{3}$ Various tests have been proposed to identify women at risks of developing preeclampsia such as the cold pressor test, the isometric hand grip exercise and the roll over test which depend on the presence of some pathophysiological changes which occur in preeclampsia. Other tests such as the measurement of urinary calcium or plasma fibronectin are based on the presence of biochemical alterations peculiar to this disease. ${ }^{4}$ 
Ideally, a screening test should be simple, inexpensive and reproducible, with high sensitivity and positive predictive value. To ensure maximum patient acceptability, it should be easy to perform and non invasive. Among the various predictors for preeclampsia, the placental location by ultrasound at $18-24$ weeks is very cost effective, non-invasive, and has a good positive predictive value. In the past two decades ultrasonography has proved to be the safest, easiest and the most accurate method for assessing the placental location. Although the exact mechanism of placental-related disorders is yet to be understood, it is believed that inadequate trophoblastic invasion is implicated in these cases. ${ }^{5}$

It is known that maternal blood traverses the placenta randomly without preformed channels, propelled by maternal arterial pressure and the process of trophoblast invasion of the spiral arteries creates low resistance uteroplacental vessels, which can accommodate the massive increase in uterine perfusion over course of gestation. Placenta being a vital link between the mother and the growing foetus plays several roles for exchange of blood, nutrients, gases, drugs, hormones, excretory products etc. When the placenta is attached on any of the lateral wall, the uteroplacental circulation has inadequate perfusion from the contralateral uterine artery. ${ }^{6}$

It is proposed that although the anastomoses between the two uterine arteries exist, there is no proof that these are functional. In women with centrally located placenta both uterine arteries demonstrated similar resistance but when the placenta is laterally located, in the majority of patients, the uteroplacental blood flows are to be met primarily by one of the uterine arteries with some contribution by other uterine artery via collateral circulation. This degree of collateral circulation, however, may not be the same in all the patients and deficient contribution may facilitate the development of preeclampsia, fetal growth restriction, or both. ${ }^{\text {? }}$

This can be reflected in abnormal waveform patterns of the uterine arteries on sonographic doppler velocimetry evaluation, with increased pulsatility and resistance indices seen. Therefore, this method of hemodynamic evaluation could possibly be used as a screening test to identify pregnancies at increased risk of preeclampsia. ${ }^{8}$

In view of the findings we conducted a prospective study to find the association of placental laterality and uterine artery resistance and development of preeclampsia.

\section{METHODS}

A prospective observational cohort study was conducted in the department of obstetrics and gynecology, over a period of 1 year from $1^{\text {st }}$ July, 2018 to $30^{\text {th }}$ June, 2019. A total of 200 antenatal subjects attending the antenatal clinic with uncomplicated singleton pregnancies at a gestation period between 18 to 24 weeks were enrolled for the study. The gestational age was determined by accurate dating methods (last menstrual period in women who are sure of dates and have regular menstrual cycles, a first trimester scan and crown - rump length for others). An informed written consent was taken from all the participants. Ethical approval was taken from the institutional ethical committee. Any patients with diagnosed chronic hypertension, early onset gestational hypertension, renal diseases, severe anemia, connective tissue disorders, diabetes mellitus, positive lupus anticoagulant, thyrotoxicosis, anti-cardiolipin antibody positive, rhesus incompatibility, multiple pregnancy, $\mathrm{H} / \mathrm{O}$ smoking, alcohol intake and drug addiction, Pregnancies with congenitally malformed fetus and Placenta previa were excluded from the study.

Yousuf $\mathrm{S}$ et al, observed that the overall risk of developing preeclampsia with laterally located placenta was 9.27 (odds ratio). ${ }^{9}$ Taking these values as reference, the minimum required sample size (with $99 \%$ power of study and $1 \%$ level of significance) was 104 patients. Taking lost to follow up as $20 \%$, sample size to be taken was 130 . To reduce margin of error, total sample size taken was 200 .

A need for regular follow up and repeat scan was explained. A detailed history and thorough general physical and obstetrical examination was performed and recorded on proforma. Blood pressures were recorded in the right arm in the sitting position with the sphygmomanometer, cuff lying at the level of heart. The systolic and diastolic (phase V i.e. complete absence of Korotkoff sounds) blood pressures were recorded.

All the participants were subjected to routine investigations of pregnancy and a trans-abdominal scan to ascertain placental location (central/lateral) using Logiq P6 GE machine with a convex probe of frequency ranging from $3.5 \mathrm{MHz}$ to $5 \mathrm{MHz}$.

Placenta was classified as central when it is equally distributed between right and left side of the uterus irrespective of anterior, posterior, or fundal position. When $\geq 70 \%$ of placental mass is to one side of the midline, it was classified as unilateral right or left placenta (lateral placenta). Based on the placental location, subjects were divided into groups.

Group A: subjects with central placenta.

Group B: subjects with unilateral (right or left) placenta.

The routine obstetric care was provided to all participants in both the groups. The subjects were followed up for development of gestational hypertension or preeclampsia as per ACOG guidelines.

All enrolled subjects were subjected to a repeat scan for uterine artery doppler between 26 to 32 weeks of gestation (the trophoblastic invasion of spiral arteries and loss of diastolic notch is well established by then. Also, 
beyond 32 weeks the difference between the two S/D ratios tends to decrease) to find out the association between placental laterality and uterine artery doppler abnormalities. Subsequent and frequent scans were advised if needed. Repeat colour doppler, fetal assessment and need for induction of labour were judged and recorded. Maternal and fetal outcomes were compared between the two groups (Group A and Group B). The maternal outcome were measured in terms of gestational hypertension, preeclampsia, preterm labour (spontaneous/induced), need for induction of labour with indication, gestation at delivery and type of delivery. The fetal outcomes measures included intrauterine growth restriction, oligohydramnios, gestation at birth, birth weight, Apgar score at 1 and 5 minutes, birth asphyxia, need for neonatal resuscitation, NICU (neonatal intensive care unit) admission if any, and duration of hospital stay.

\section{Statistical analysis}

Categorical variables were presented in number and percentage (\%) and continuous variables were presented as mean $\pm \mathrm{SD}$ and median. Normality of data was tested by Kolmogorov-Smirnov test. If the normality was rejected then non parametric test was used.

\section{Statistical tests applied were as follows}

- Quantitative variables were compared using unpaired t-test/Mann-Whitney test (when the data sets were not normally distributed)

- Qualitative variables were compared using ChiSquare test /Fisher's exact test

- Univariate and multivariate logistic regression were used to find out the risk factors of developing preeclampsia.

A $p$ value of $<0.05$ was considered statistically significant.

The data was entered in MS Excel spreadsheet and analysis was done using statistical package for social sciences (SPSS) version 21.0.

\section{RESULTS}

Among 200 study patients, most were in the age group of 21-29 years $(61.5 \%)$, residing in rural areas. Around 79\% had percapita income more than the poverty line. The demographic and clinical characteristics have been shown in Table 1 .

On doppler, placenta was central in $162(81 \%)$ patients and lateral in $38(19 \%)$ patients. Study found that the placental laterality showed significant association with different doppler parameters at different gestational age as shown in Table 2.

Study found no significant association of placental laterality with hypertension in pregnancy (Table 3).
Table 1: Demographic and clinical characteristics.

\begin{tabular}{|c|c|c|}
\hline Characteristics & Frequency & $\%$ \\
\hline \multicolumn{3}{|l|}{ Age distribution in years } \\
\hline$<20$ & 14 & $7.00 \%$ \\
\hline $21-29$ & 123 & $61.50 \%$ \\
\hline $30-39$ & 62 & $31.00 \%$ \\
\hline$\geq 40$ & 1 & $0.50 \%$ \\
\hline \multicolumn{3}{|l|}{ Gravidity } \\
\hline Primigravida & 89 & $44.50 \%$ \\
\hline G 2 & 69 & $34.50 \%$ \\
\hline G 3 & 29 & $14.50 \%$ \\
\hline Gravida 4 or more & 13 & $6.50 \%$ \\
\hline \multicolumn{3}{|l|}{ Residence } \\
\hline Rural & 151 & $75.50 \%$ \\
\hline Urban & 49 & $24.50 \%$ \\
\hline \multicolumn{3}{|l|}{ Per capita income } \\
\hline Above poverty line & 158 & $79.00 \%$ \\
\hline Below poverty line & 42 & $21.00 \%$ \\
\hline \multicolumn{3}{|l|}{ Body mass index $\left(\mathrm{kg} / \mathrm{m}^{2}\right)$} \\
\hline Underweight $(\mathrm{BMI}<18.5)$ & 14 & $7.00 \%$ \\
\hline Normal (BMI 18.5-22.9) & 124 & $62.00 \%$ \\
\hline Overweight (BMI 23-24.9) & 38 & $19.00 \%$ \\
\hline Obese $(\mathrm{BMI} \geq 25)$ & 24 & $12.00 \%$ \\
\hline \multicolumn{3}{|l|}{ Veg/non-veg } \\
\hline Veg & 154 & $77.00 \%$ \\
\hline Non-veg & 46 & $23.00 \%$ \\
\hline \multicolumn{3}{|l|}{ Significant obstetric history } \\
\hline No & 177 & $88.50 \%$ \\
\hline Yes & 23 & $11.50 \%$ \\
\hline Primary infertility & 3 & $13.4 \%$ \\
\hline Secondary infertility & 1 & $4.35 \%$ \\
\hline Gestational hypertension & 1 & $4.35 \%$ \\
\hline $\begin{array}{l}\text { Gestational hypertension with } \\
\text { previous caesarean }\end{array}$ & 1 & $4.35 \%$ \\
\hline Eclampsia & 1 & $4.35 \%$ \\
\hline Eclampsia with previous caesarea & a 1 & $4.35 \%$ \\
\hline Previous caesarean & 9 & $39.13 \%$ \\
\hline Previous 2 abortions & 1 & $4.35 \%$ \\
\hline Previous 3 abortions & 1 & $4.35 \%$ \\
\hline Previous malformed fetus & 2 & $8.7 \%$ \\
\hline Previous IUFD & 1 & $4.35 \%$ \\
\hline Previous history of neonatal death & h 1 & $4.35 \%$ \\
\hline \multicolumn{3}{|l|}{ Past medical history } \\
\hline No & 173 & $86.50 \%$ \\
\hline Yes & 27 & $13.50 \%$ \\
\hline Subclinical hypothyroidism & 17 & $62.96 \%$ \\
\hline Hepatitis B positivity & 2 & $7.41 \%$ \\
\hline ATT intake & 2 & $7.41 \%$ \\
\hline Bronchial asthma & 2 & $7.41 \%$ \\
\hline Epilepsy & 2 & $7.41 \%$ \\
\hline Scabies & 1 & $3.7 \%$ \\
\hline Migraine & 1 & $3.7 \%$ \\
\hline \multicolumn{3}{|l|}{ History of surgery in the past } \\
\hline No & 187 & $93.50 \%$ \\
\hline Yes & 13 & $6.50 \%$ \\
\hline Cholecystectomy & 10 & $76.92 \%$ \\
\hline Ovarian cystectomy & 3 & $23.08 \%$ \\
\hline
\end{tabular}


Table 2: Association of placental laterality with doppler features at different gestational ages.

\begin{tabular}{|c|c|c|c|c|c|}
\hline \multirow{2}{*}{$\begin{array}{l}\text { At gestation } 26 \text { weeks to } 27+6 \\
\text { weeks }\end{array}$} & \multicolumn{2}{|c|}{ Central $(n=10)$} & \multicolumn{2}{|c|}{ Lateral $(\mathrm{n}=5)$} & \multirow{2}{*}{ p value } \\
\hline & Mean \pm SD & Median (IQR) & Mean \pm SD & Median (IQR) & \\
\hline Resistance index (right uterine artery) & $0.37 \pm 0.09$ & $0.36(0.330-0.390)$ & $0.27 \pm 0.05$ & $0.23(0.230-0.330)$ & 0.028 \\
\hline Pulsatility index (right uterine artery) & $0.72 \pm 0.47$ & $0.53(0.500-0.940)$ & $0.37 \pm 0.13$ & $0.27(0.270-0.510)$ & 0.063 \\
\hline $\mathrm{S} / \mathrm{D}$ ratio (right uterine artery) & $1.67 \pm 0.31$ & $1.6(1.500-1.800)$ & $1.38 \pm 0.11$ & $1.3(1.300-1.500)$ & 0.019 \\
\hline Resistance index (left uterine artery) & $0.33 \pm 0.08$ & $0.33(0.230-0.360)$ & $0.37 \pm 0.03$ & $0.39(0.330-0.390)$ & 0.229 \\
\hline Pulsatility index (left uterine artery) & $0.64 \pm 0.5$ & $0.46(0.270-0.730)$ & $0.49 \pm 0.06$ & $0.53(0.420-0.530)$ & 0.664 \\
\hline $\mathrm{S} / \mathrm{D}$ ratio (left uterine artery) & $1.56 \pm 0.19$ & $1.55(1.500-1.600)$ & $1.56 \pm 0.05$ & $1.6(1.500-1.600)$ & 0.846 \\
\hline \multirow{2}{*}{ At gestation 28 weeks to $29+6$ weeks } & \multicolumn{2}{|c|}{ Central $(n=51)$} & \multicolumn{2}{|c|}{ Lateral $(n=17)$} & \multirow{2}{*}{ p value } \\
\hline & Mean \pm SD & Median (IQR) & Mean \pm SD & Median (IQR) & \\
\hline Resistance index (right uterine artery) & $0.46 \pm 0.13$ & $0.45(0.400-0.500)$ & $0.56 \pm 0.39$ & $0.5(0.375-0.510)$ & 0.365 \\
\hline Pulsatility index (right uterine artery) & $0.67 \pm 0.22$ & $0.6(0.585-0.795)$ & $0.75 \pm 0.31$ & $0.7(0.575-1.070)$ & 0.448 \\
\hline $\mathrm{S} / \mathrm{D}$ ratio (right uterine artery) & $1.93 \pm 0.36$ & $1.9(1.700-2)$ & $2.15 \pm 0.68$ & $2(1.775-2.100)$ & 0.357 \\
\hline Resistance index (left uterine artery) & $0.46 \pm 0.18$ & $0.47(0.400-0.500)$ & $0.51 \pm 0.21$ & $0.47(0.423-0.500)$ & 0.742 \\
\hline Pulsatility index (left uterine artery) & $0.69 \pm 0.21$ & $0.7(0.525-0.838)$ & $0.64 \pm 0.16$ & $0.6(0.580-0.695)$ & 0.255 \\
\hline $\mathrm{S} / \mathrm{D}$ ratio (left uterine artery) & $1.98 \pm 0.38$ & $1.9(1.700-2.100)$ & $1.94 \pm 0.26$ & $1.9(1.700-2.200)$ & 0.909 \\
\hline \multirow{2}{*}{ At gestation 30 weeks to 32 weeks } & \multicolumn{2}{|c|}{ Central $(n=101)$} & \multicolumn{2}{|c|}{ Lateral $(n=16)$} & \multirow{2}{*}{ p value } \\
\hline & Mean \pm SD & Median (IQR) & Mean \pm SD & Median (IQR) & \\
\hline Resistance index (right uterine artery) & $0.41 \pm 0.08$ & $0.4(0.390-0.463)$ & $0.38 \pm 0.11$ & $0.4(0.310-0.450)$ & 0.396 \\
\hline Pulsatility index (right uterine artery) & $0.58 \pm 0.15$ & $0.6(0.500-0.620)$ & $0.48 \pm 0.13$ & $0.5(0.325-0.600)$ & 0.024 \\
\hline S/D ratio (right uterine artery) & $1.77 \pm 0.23$ & $1.78(1.600-1.900)$ & $1.65 \pm 0.18$ & $1.6(1.500-1.800)$ & 0.045 \\
\hline Resistance index (left uterine artery) & $0.41 \pm 0.13$ & $0.4(0.365-0.460)$ & $0.45 \pm 0.06$ & $0.48(0.395-0.500)$ & 0.023 \\
\hline Pulsatility index (left uterine artery) & $0.6 \pm 0.26$ & $0.6(0.500-0.620)$ & $0.63 \pm 0.17$ & $0.6(0.510-0.750)$ & 0.344 \\
\hline $\mathrm{S} / \mathrm{D}$ ratio (left uterine artery) & $1.76 \pm 0.22$ & $1.8(1.600-1.900)$ & $1.83 \pm 0.24$ & $1.79(1.600-2.050)$ & 0.322 \\
\hline
\end{tabular}

Table 3: Association of placental laterality with hypertension in pregnancy.

\begin{tabular}{|c|c|c|c|c|}
\hline & \multicolumn{3}{|l|}{ Placental laterality } & \multirow{2}{*}{ p value } \\
\hline & Central $(n=162)$ & Lateral $(n=38)$ & Total $(n=200)$ & \\
\hline \multicolumn{5}{|c|}{ Gestational hypertension } \\
\hline No & $162(100.00 \%)$ & $38(100.00 \%)$ & $200(100.00 \%)$ & \multirow[b]{2}{*}{-} \\
\hline Yes & $0(0.00 \%)$ & $0(0.00 \%)$ & $0(0.00 \%)$ & \\
\hline \multicolumn{5}{|c|}{ Preeclampsia without severe features } \\
\hline No & $161(99.38 \%)$ & $38(100.00 \%)$ & $199(99.50 \%)$ & \multirow{2}{*}{1} \\
\hline Yes & $1(0.62 \%)$ & $0(0.00 \%)$ & $1(0.50 \%)$ & \\
\hline \multicolumn{5}{|c|}{ Eclampsia } \\
\hline No & $162(100.00 \%)$ & $38(100.00 \%)$ & $200(100.00 \%)$ & \multirow[b]{2}{*}{-} \\
\hline Yes & $0(0.00 \%)$ & $0(0.00 \%)$ & $0(0.00 \%)$ & \\
\hline
\end{tabular}

Table 4: Association of placental laterality with fetal outcome.

\begin{tabular}{|llll|}
\hline \multicolumn{1}{|l}{} & $\begin{array}{l}\text { Placental laterality } \\
\text { Central }(\mathbf{n}=\mathbf{1 6 2})\end{array}$ & Lateral $(\mathbf{n = 3 8 )}$ & Total (n= 200) \\
\hline Other antenatal events & & & \\
\hline Decreased fetal movements & $1(0.62 \%)$ & $0(0.00 \%)$ & $1(0.50 \%)$ \\
\hline Oligohydramnios & $0(0.00 \%)$ & $1(2.63 \%)$ & $1(0.50 \%)$ \\
\hline Moderate anaemia & $1(0.62 \%)$ & $0(0.00 \%)$ & $1(0.50 \%)$ \\
\hline None & $160(98.77 \%)$ & $37(97.37 \%)$ & $197(98.50 \%)$ \\
\hline Intrapartum fetal complications & & & \\
\hline NRFHR & $2(1.23 \%)$ & $2(5.26 \%)$ & $4(2.00 \%)$ \\
\hline NRFHR with MSL & $4(2.47 \%)$ & $0(0.00 \%)$ & $4(2.00 \%)$ \\
\hline MSL & $8(4.94 \%)$ & $0(0.00 \%)$ & $8(4.00 \%)$ \\
\hline None & $148(91.36 \%)$ & $36(94.74 \%)$ & $184(92.00 \%)$ \\
\hline Colour of liquor & & & \\
\hline Clear & $150(92.59 \%)$ & $38(100.00 \%)$ & $188(94.00 \%)$ \\
\hline Meconium stained & $12(7.41 \%)$ & $0(0.00 \%)$ & $12(6.00 \%)$ \\
\hline
\end{tabular}




\begin{tabular}{|c|c|c|c|c|}
\hline & \multicolumn{3}{|l|}{ Placental laterality } & \multirow{2}{*}{ p value } \\
\hline & Central $(n=162)$ & Lateral $(n=38)$ & Total $(n=200)$ & \\
\hline \multicolumn{5}{|c|}{ Birth weight (in kg) } \\
\hline $1-1.499$ & $1(0.62 \%)$ & $0(0.00 \%)$ & $1(0.50 \%)$ & \multirow{4}{*}{0.198} \\
\hline $1.5-2.499$ & $26(16.05 \%)$ & $5(13.16 \%)$ & $31(15.50 \%)$ & \\
\hline $2.5-3.5$ & $135(83.33 \%)$ & $32(84.21 \%)$ & $167(83.50 \%)$ & \\
\hline$>3.5$ & $0(0.00 \%)$ & $1(2.63 \%)$ & $1(0.50 \%)$ & \\
\hline \multicolumn{5}{|c|}{ Apgar scores 1 minute } \\
\hline Mean \pm SD & $7 \pm 0$ & $7 \pm 0$ & $7 \pm 0$ & \multirow{2}{*}{1} \\
\hline Median (IQR) & $7(7-7)$ & $7(7-7)$ & $7(7-7)$ & \\
\hline \multicolumn{5}{|c|}{ Apgar scores 5 minute } \\
\hline Mean \pm SD & $8.99 \pm 0.08$ & $9 \pm 0$ & $8.99 \pm 0.07$ & \multirow{2}{*}{0.628} \\
\hline Median (IQR) & $9(9-9)$ & $9(9-9)$ & $9(9-9)$ & \\
\hline \multicolumn{5}{|c|}{ NICU admission } \\
\hline Yes & $4(2.47 \%)$ & $0(0.00 \%)$ & $4(2.00 \%)$ & \multirow{2}{*}{1} \\
\hline No & $158(97.53 \%)$ & $38(100.00 \%)$ & $196(98.00 \%)$ & \\
\hline
\end{tabular}

Table 5: Association of placental laterality with maternal outcome.

\begin{tabular}{|c|c|c|c|c|}
\hline & \multicolumn{3}{|l|}{ Placental laterality } & \multirow{2}{*}{ p value } \\
\hline & Central $(n=162)$ & Lateral $(n=38)$ & Total $(n=200)$ & \\
\hline \multicolumn{5}{|l|}{ Onset of labour } \\
\hline Spontaneous & $149(91.98 \%)$ & $32(84.21 \%)$ & $181(90.50 \%)$ & \multirow{2}{*}{0.142} \\
\hline Induced & $13(8.02 \%)$ & $6(15.79 \%)$ & $19(9.50 \%)$ & \\
\hline \multicolumn{5}{|l|}{ Indication for IOL } \\
\hline Post dated & $8(61.54 \%)$ & $5(83.33 \%)$ & $13(68.42 \%)$ & \multirow{5}{*}{0.313} \\
\hline ICP & $2(15.38 \%)$ & $0(0.00 \%)$ & $2(10.53 \%)$ & \\
\hline PPROM with features of chorioamnionitis & $2(15.38 \%)$ & $0(0.00 \%)$ & $2(10.53 \%)$ & \\
\hline Oligohydramnios with poor BPP & $0(0.00 \%)$ & $1(16.67 \%)$ & $1(5.26 \%)$ & \\
\hline Preeclampsia with severe features & $1(7.69 \%)$ & $0(0.00 \%)$ & $1(5.26 \%)$ & \\
\hline \multicolumn{5}{|l|}{ Mode of delivery } \\
\hline Normal vaginal delivery & $132(81.48 \%)$ & $29(76.32 \%)$ & $161(80.50 \%)$ & 0.469 \\
\hline Instrumental vaginal delivery & $3(1.85 \%)$ & $0(0.00 \%)$ & $3(1.50 \%)$ & 1 \\
\hline LSCS & $27(16.67 \%)$ & $9(23.68 \%)$ & $36(18.00 \%)$ & 0.311 \\
\hline \multicolumn{5}{|l|}{ Indication of caesarean delivery } \\
\hline AFD & $11(40.74 \%)$ & $2(22.22 \%)$ & $13(36.12 \%)$ & \multirow{11}{*}{0.187} \\
\hline NRFHR & $3(11.11 \%)$ & $2(22.22 \%)$ & $5(13.89 \%)$ & \\
\hline NRFHR with MSL & $2(7.41 \%)$ & $0(0 \%)$ & $2(5.56 \%)$ & \\
\hline MSL & $6(22.22 \%)$ & $0(0 \%)$ & $6(16.67 \%)$ & \\
\hline Breech presentation & $9(33.33 \%)$ & $1(11.11 \%)$ & $10(27.78 \%)$ & \\
\hline Breech in labour & $8(29.63 \%)$ & $1(11.11 \%)$ & $9(25 \%)$ & \\
\hline Breech presentation with PE with severe features & $1(3.7 \%)$ & $0(0 \%)$ & $1(2.78 \%)$ & \\
\hline Prior caesarean section & $5(18.52 \%)$ & $4(44.44 \%)$ & $9(25 \%)$ & \\
\hline Previous LSCS with thin scar & $3(11.11 \%)$ & $0(0 \%)$ & $3(8.33 \%)$ & \\
\hline Refusal for VBAC & $2(7.41 \%)$ & $4(44.44 \%)$ & $6(16.67 \%)$ & \\
\hline Failed IOL & $2(7.41 \%)$ & $2(22.22 \%)$ & $4(11.11 \%)$ & \\
\hline
\end{tabular}

Various fetal complications, birth weight, Apgar scores and NICU admission were comparable among women with central or lateral placenta $(\mathrm{p}>0.05)$ as shown in Table 4.

Even the maternal outcomes like mode of delivery, onset of labor, indication of labor induction and caesarean deliveries were comparable among women with central or lateral placenta $(\mathrm{p}>0.05)$ as shown in Table 5.
In this study, on applying univariate logistic regression analysis, to the above variables which could have been confounding factors, previous history of PIH (which includes gestational hypertension, preeclampsia and eclampsia) was a significant risk factor for development of preeclampsia in the present study. It had a $\mathrm{p}$ value of 0.002 (which was less than 0.05 ), with a $95 \%$ confidence interval of 7.668-26507.341 and odds ratio 168.43 (Table $6)$. 
Table 6: Regression analysis of the variables for prediction of hypertension in pregnancy.

\begin{tabular}{|lllllll|}
\hline Variables & B & S.E. & p value & Odds ratio & \multicolumn{2}{c|}{ L5\% C.I. for odds ratio } \\
\hline Age $(>40)$ & 3.787 & 2.451 & 0.112 & 44.11 & 0.260 & Upper \\
\hline BMI $(>30)$ & 3.271 & 2.068 & 0.149 & 26.33 & 0.164 & 658.790 \\
\hline Primigravida & -0.888 & 1.648 & 0.565 & 0.41 & 0.003 & 7.811 \\
\hline Type of infertility & 2.673 & 1.858 & 0.210 & 14.481 & 0.094 & 315.599 \\
\hline previous obstetric history of PIH & 5.127 & 1.790 & 0.002 & 168.43 & 7.668 & 26507.341 \\
\hline Placental laterality & & & & & & \\
\hline Central & & & & 1 & & \\
\hline Lateral & 0.335 & 1.660 & 0.843 & 1.398 & 0.010 & 26.735 \\
\hline
\end{tabular}

BMI: Body mass index, PIH: Pregnancy induced hypertension, B: Beta coefficient, SE: Standard error, CI: Confidence interval.

\section{DISCUSSION}

The precise pathogenesis of preeclampsia remains to be a subject of research, but it is believed that it is multifactorial. In order to avoid the bias due to the other factors, the subjects with medical co-morbidities like chronic hypertension, diabetes mellitus and chronic renal diseases were excluded in the present study.

The present study suggested that the central placenta was more common than the lateral ( $81 \%$ versus $19 \%)$. Previously, many authors suggested that central placenta is more common; However, the studies by Kofinas et al, Liberati et al and Preety et al found lateral placentation to be more common. ${ }^{10-12}$ These differences may be due to differences in the criteria defining central and lateral placenta. In this study, lateral placenta was considered only when $70 \%$ or more of the placenta was on one side of the uterine cavity, which was in accordance to the Indian study by Yousuf et al. ${ }^{9}$ In comparison, Devarajan et al assigned the placental position as central/fundal or lateral using the maternal aorta as midline. ${ }^{13}$

The association between placental laterality and development of PIH has been examined previously with controversial results. Few showed significant relationship between laterally located placenta and preeclampsia whereas few found no relation between the two. ${ }^{9,11,14-16}$ Study did not observe any association between placental laterality and development of preeclampsia. A single subject developed preeclampsia in the present study and the placenta was central in this subject.

Most of the studies had excluded the subjects with current pregnancy complications and previous medical disorders. Prior preeclampsia is an independent and important risk factor for development of preeclampsia with $25 \%$ recurrence. In this study however this was not excluded, prior history of PIH (gestational hypertension and eclampsia) was present in $4(2 \%)$ subjects, all of which belonged to the central placenta group and ultimately one of these subjects developed preeclampsia.
The Doppler indices of the subjects enrolled for the study were normal except increased pulsatility index of the right and left uterine artery in a subject with central placenta. Study findings are in contrast to the findings of Kofinaset al, who studied placental laterality according to the uterine artery flow velocity wave forms. ${ }^{10}$ They observed that the placenta was located laterally in the majority of subjects with abnormal uterine artery flow velocity wave forms. Regardless of the vessel examined (left/right uterine artery or the mean of two sides), 70 to $73 \%$ of subjects with abnormal flow velocity waveforms had unilaterally located placenta. In the presence of preeclampsia and abnormal uterine artery flow velocity wave forms $(n=20), 16(80 \%)$ had unilateral placenta and only four $(20 \%)$ had a centrally located placenta. in the presence of IUGR with abnormal uterine artery flow velocity wave forms $(\mathrm{n}=18), 15(83 \%)$ had unilateral placenta and only three $(17 \%)$ had central placenta. The reason for this discrepancy could be due to the difference in the study population. Although the study was first to demonstrate a significant relationship between the placental laterality and the presence of preeclampsia, IUGR or both, the data of the Doppler indices of the uterine artery was not stratified in relation to the presence or absence of pregnancy complications (i.e. diabetes, hypertension, etc.) and the duration of the diseases. The latter itself can alter the uterine hemodynamics.

Consistent with the observations in a study conducted by Devarajan et al, and Magann et al (the largest completed study), study found no association between lateral placentation and LBW. ${ }^{13,15}$ Though the location of the placenta is a potential predictor of LBW dates back to the first study by Kofinas et al. ${ }^{10}$ These authors reported 2.7 times risk of LBW and PE in association with lateral placental location. In pregnancies complicated by LBW or $\mathrm{PE}, 75 \%$ of placenta were laterally located and in uncomplicated pregnancies, $50 \%$ of placenta were laterally located, the low resistance is limited to uterine artery that is ipsilateral to the placental location, and the collateral blood supply from the contralateral uterine artery may be less efficient. These aberrations in blood flow may be associated with PE and LBW. 
Thus, while LBW affected fetuses may be more likely to have a lateral placenta, lateral placenta do not necessarily predispose to babies with LBW and PE. The overall body of data suggests that lateral placental location in the second trimester of pregnancy doesn't predict the risk of $\mathrm{PE}$ and LBW.

This study found no association in the mean gestation at the time of delivery with placental laterality $(\mathrm{p}>0.05)$. This was consistent with the previous studies. ${ }^{14-16}$

It was observed that 12 subjects had meconium stained liquor and all of them had a central placenta. $7.41 \%$ $(12 / 162)$ subjects with central placenta had meconium stained liquor on the contrary none of the subjects with a lateral placenta had meconium stained liquor. Study results were in contrast to Vaillant et al, who discovered an increased risk of fetal distress in labor with laterally located placenta. ${ }^{17}$ The difference could be due to the more number of subjects with a central placenta $(162 / 200$ i.e. $81 \%$ ) in the present study and Vaillant et al, compared 75 of the laterally implanted placenta with 21 females with centrally implanted. ${ }^{17}$

In this study, on applying univariate logistic regression analysis, only previous history of PIH (which includes gestational hypertension, preeclampsia and eclampsia) was a significant risk factor for development of preeclampsia with an odds ratio 168.43. Placental laterality showed no significant increased risk for hypertension in pregnancy.

In a similar study done by Yousuf et al, it was observed that primary infertility ( $p$ value 0.003 ) and lateral placenta $(p$ value $<0.001)$ were independent risk factors for development of preeclampsia. ${ }^{9}$ After applying logistic regression, they found that overall risk of developing preeclampsia with laterally located placenta was 9.27 (odds ratio) with $95 \%$ confidence interval of 4.30619.978 .

In the present study since only one subject developed preeclampsia and this subject belonged to the central placenta group, the sensitivity of the test was zero percent. Since only 1 patient had preeclampsia so ROC curve for abnormal uterine Doppler findings cannot be constructed and hence their predictive value could not be determined.

This is in contrast to the study by Jaiswal $\mathrm{J}$ et al, where high incidence of preeclampsia was associated with lateral placenta i.e. $51.3 \%(19 / 37)$ as compared to central placenta i.e. $9.7 \%(9 / 93)$ in their study. ${ }^{18}$ Hence, the sensitivity of the test came out to be $67.86 \%$. Predictive value of uterine artery Doppler was not studied as they did not subject their patients to Doppler velocimetry. However, they too in their conclusion firmly believe that larger studies are required for finding the association of the placental laterality and development of preeclampsia.
Limitations of the study was to since only one subject developed pre-eclampsia, the main limitation of the study was the sample size which prevented from finding any definite risk association of placental laterality with hypertension in pregnancy.

\section{CONCLUSION}

It can be concluded that the maternal and fetal outcomes are independent of the placenta laterality. The doppler characteristics and placenta laterality did not show any increased risk for hypertension in pregnancy. However future studies are recommended with large sample size including more women with diagnosed hypertension in the pregnancy so that a better association can be derived with placenta laterality and doppler characteristics.

Funding: No funding sources Conflict of interest: None declared

Ethical approval: The study was approved by the Institutional Ethics Committee

\section{REFERENCES}

1. Magee LA, Dadelszen P von, Stones W, Mathai M. The FIGO textbook of pregnancy hypertension: an evidence-based guide to monitoring, prevention and Management; 2016.

2. Rastogi A. Preeclampsia. National Health Portal of India, 2016. Available at: https:/www.nhp.gov.in/disease/gynecology-andobstetrics/preeclampsia. Accessed on $12^{\text {th }}$ August 2019.

3. World Health Organization. WHO recommendations for prevention and treatment of pre-eclampsia and eclampsia, 2011. Available at: http://whqlibdoc.who.int/publications/2011/9789241 548335_eng.pdf. Accessed on $12^{\text {th }}$ August 2019.

4. Munge A, Satia M. Urinary calcium to creatinine ratio to predict preeclampsia and use of calcium supplementation to prevent preeclampsia. Int $\mathrm{J}$ Reprod Contracept Obstet Gynecol. 2016;104:13805.

5. Wallace AE, Whitley GS, Thilaganathan B, Cartwright JE. Decidual natural killer cell receptor expression is altered in pregnancies with impaired vascular remodeling and a higher risk of preeclampsia. J Leukoc Biol. 2015;97(1):79-86.

6. North RA, Ferrier C, Long D, Townend K, KincaidSmith P. Uterine artery Doppler flow velocity waveforms in the second trimester for the prediction of preeclampsia and fetal growth retardation. Obstet Gynecol. 1994;83(3):378-86.

7. Pedroso M, Palmer K, Hodges R, Costa F, Rolnik D. Uterine artery Doppler in screening for preeclampsia and fetal growth restriction. Rev Bras Ginecol Obstet. 2018;40(05):287-93.

8. Yu CKH, Khouri O, Onwudiwe N, Spiliopoulos Y, Nicolaides KH. For the fetal medicine foundation second-trimester screening group. Prediction of pre- 
eclampsia by uterine artery Doppler imaging: relationship to gestational age at delivery and smallfor-gestational age. Ultrasound Obstet Gynecol. 2008;31(3):310-3.

9. Yousuf S, Ahmad A, Qadir S, Gul S, Tali SH, Shaheen F, et al. Utility of placental laterality and uterine artery Doppler abnormalities for prediction of preeclampsia. J Obstet Gynecol India. 2016;66(S1):212-6.

10. Kofinas D, Penry M, Swain M, Hatjis CG. Effect of placental laterality on uterine artery resistance and development of preeclampsia and intrauterine growth retardation. Am J Obstet Gynecol. 1989;161(6):1536-9.

11. Liberati $M$, Rotmensch S, Zannolli P, Perrino S, Celentano C, Tiboni GM, et al. Uterine artery Doppler velocimetry in pregnant women with lateral placentas. J Perinat Med. 1997;25(2):133-8.

12. Preety A, Phalguni K, Nounenuo T. Study on relation between placental laterality in second trimester ultrasound and development of preeclampsia at term. J Evol Med Dent Sci. 2015;4(104):16926-8.

13. Devarajan K, Kives S, Ray JG. Placental location and newborn weight. J Obstet Gynaecol Can. 2012;34(4):325-9.

14. Seckin KD, Cakmak B, Karsli MF, Yeral MI, Gultekin IB, Oz M, et al. Is lateral localisation of placenta a risk factor for adverse perinatal outcomes? J Obstet Gynaecol. 2015;35(7):696-8.

15. Magann EF, Doherty DA, Turner K, Lanneau GS, Morrison JC, Newnham JP. Second trimester placental location as a predictor of an adverse pregnancy outcome. J Perinatol. 2007;27:9-14.

16. Contro E, Maroni E, Cera E, Youssef A, Bellussi F, Pilu $G$, et al. Unilaterally increased uterine artery resistance, placental location and pregnancy outcome. Eur J Obstet Gynecol Reprod Biol. 2010;153(2):143-7.

17. Vaillant P, Best MC, Cynober E, Devulder G. Pathological uterine readings when the placenta is laterally situated. J Gynecol Obstet Biol Reprod. 1993;22:301-7.

18. Jaiswal J, Jaiswal A, Nagaria $T$, Ramteke A. Prediction of pregnancy induced hypertension by USG guided placental localization. J Evol Med Dent Sci. 2015;4(81):14163-72.

Cite this article as: Rana A, Thakur R, Rao R. A prospective observational study to determine the utility of placental laterality for prediction of preeclampsia in pregnancy. Int $\mathrm{J}$ Reprod Contracept Obstet Gynecol 2020;9:1664-71. 